\title{
Huellas de la Cortesía: Reparaciones y Estrategias de Consenso en el Habla de Mérida
}

\author{
(Marcas da Cortesia: Reparações e Estratégias de \\ Consenso na Fala de Mérida) \\ (Marks of Courtesy: Corrections and Consensus-Building \\ Strategies in the Speech of Mérida)
}

\author{
Alexandra Alvarez \\ (Universidad deLosAndes-xandra@cantv.net)
}

\begin{abstract}
This study focusses on the rules of politeness of a spoken corpus, evidenced by the repairs of their transgression and also by speaker's intents to concert agreements between participants and evade conflict. We also inquired about the ideal sought through those norms: in positive politeness, that of a friendly person, who has knowledge of his/ her language and evades inappropriate topics. In negative politeness, that of a person who defends, although gently, her own space and respects that of the others.
\end{abstract}

KEY-WORDs: Politeness; Discourse Analysis; Norms; Identity.

RESUMEN: En este trabajo estudiamos las normas de la cortesía en un corpus oral, evidenciadas a través de las reparaciones hechas a las transgresiones de esas normas y también a través de los intentos de los hablantes de concertar acuerdos entre ellos y evadir el conflicto. Asimismo, indagamos sobre el ideal de persona que proyectan esas normas: en la cortesía positiva, el de una persona amable, conocedora de la lengua, que evade los temas impropios; en la cortesía negativa, la imagen de una persona que también sabe salir firme, aunque suavemente, a la defensa del espacio propio y respeta el de los otros.

PalabRas-Clave: Cortesía; Análisis del Discurso; Normas; Identidad.

Las normas sociales tienen, para su estudio, la dificultad de que no siempre están escritas. Esto sucede con las normas de cortesía verbal: Si bien existen los manuales de cortesía, ellos se dedican al lenguaje solo en

D.E.L.T.A., 18:2, $2002(173-202)$ 
parte; además, la existencia de un manual no daría fe del cumplimiento de sus normas y es ésta la razón de este trabajo sobre la cortesía verbal tal como ésta se manifiesta en un corpus específico de habla oral (Domínguez \& Mora, 1998). Nos proponemos aquí, en primer lugar, definir el carácter institucional de la cortesía, discutir la relación de las normas de cortesía con las normas gramaticales; en segundo lugar estudiar las normas de la cortesía verbal en Mérida a partir de las infracciones de esas mismas normas y en tercer lugar, ver cuál es su papel en la construcción de la imagen, al tratar de inferir cuál es la identidad que los hablantes merideños buscan representar.

El Diccionario de la Real Academia Española define la cortesía como la "Demostración o acto con el que se manifiesta la atención, respeto o afecto que tiene una persona a otra" y relaciona la palabra con otras voces, como son cortesanía la 'urbanidad, agrado, comedimiento', con urbanidad que es 'atención, comedimiento y buen modo'. En estas voces encontramos tres ideas centrales: la idea de acto o acción, la de respeto, contención o moderación y la de distinción o buenas maneras. María Moliner define la cortesía como el conjunto de reglas mantenidas en el trato social con las que las personas se muestran entre sí consideración y respeto, añadiéndose entonces a las ideas anteriores, también la de norma.

Por otra parte, los tratados lingüísticos sobre cortesía, como el de Brown y Levinson (1987) la estudian como respuesta a la necesidad que tienen los grupos humanos de controlar su agresión interna y retener a la vez ese potencial, una "actitud profiláctica" tanto para el control social interno, como para las relaciones competitivas externas con otros grupos, y señalan que la cortesía, la deferencia y el tacto tienen un significado sociológico que trasciende el nivel del comportamiento en la mesa y los libros de etiqueta (Brown \& Levinson, 1987:1).

Haverkate (1997), en su libro sobre la cortesía verbal, añade a estas características la de universalidad, pues la cortesía parece existir en todas las civilizaciones, aunque haya variación en las diferentes culturas con respecto a sus normas internas. De este modo, entendemos también que está relacionada con la identidad individual y social: la cortesía sirve para construir nuestra imagen personal y la del grupo al que pertenecemos; parece así obedecer a la función de identificación que Fishman (1972) atribuye al lenguaje, base de la cortesía, porque aquéles uno de los sistemas que sirve para identificar un grupo y distinguirlo de los demás. 
Nos encontramos, entonces, con un conjunto de actos simbólicos, gestuales o verbales, que expresan sentimientos de aprecio y/o respeto normados o codificados, y que de alguna manera son conscientes porque implican una contención, una medida. Estos actos cumplen una labor en relación con la construcción de la identidad personal y social, a la vez que sirven para regular la conducta entre los grupos humanos y evitar los conflictos entre sus miembros. Todo lo anterior se traduce de una manera más coherente si definimos la cortesía como una institución subsidiaria del lenguaje humano que contribuye tanto a la formación de la identidad, como a la construcción y mantenimiento del grupo.

\section{La cortesía como institución social}

Decimos que la cortesía es subsidiaria del lenguaje humano porque el lenguaje está en la base de todas las instituciones sociales, por ser el sistema simbólico por excelencia. Según Searle, para que haya hechos institucionales tiene que existir, al menos, una forma primitiva de lenguaje, por lo que el lenguaje goza de primacía lógica sobre las demás instituciones (Searle, 1997: 75). La premisa fundamental de esta aseveración es la de que el lenguaje es un hecho social, exterior a la conciencia humana individual: su existencia no depende de la conciencia de un sólo individuo, ni de su psicología personal (cf. Dürkheim, 1993).

Se ha dicho que los hechos sociales son obligantes. Los fenómenos sociales, según Dürkheim, son "cosas” que tienen existencia propia y que el individuo encuentra completamente formadas cuando nace; participan de la supremacía material y moral que la sociedad tiene sobre sus miembros, por lo que no pueden modificarse sino en forma colectiva; la consciencia que se tiene de esos hechos es también colectiva y no individual (Dürkheim, 1993:28). Así podemos contar por ejemplo, entre los hechos sociales al dinero, la religión, el lenguaje y quizás también a la cortesía.

Aún más, se atribuye a las palabras el hecho de hacer $\operatorname{cosas}^{1}$ : la institución del matrimonio está basada en el lenguaje de modo que su acto constitutivo se realiza sólamente a partir de la pronunciación del enunciado: "yo los declaro marido y mujer". A partir de allí surgen una serie de

1 Véase Austin, 1982. Cómo hacer cosas con palabras. Barcelona: Paidós. 
derechos y deberes. Así como el lenguaje está en la base del matrimonio, también parece estar en la base de la cortesía. Los actos de la cortesía pueden ser gestuales o verbales. Nos quitamos el sombrero en señal de respeto al otro, nos inclinamos ante él, besamos sus manos o sus pies con el gesto o con la palabra: me quito el sombrero, chapeau, beso sus manos, beso sus pies, me inclino ante usted son también fórmulas verbales de cortesía.

\subsection{Norma lingüistica y norma social}

Las instituciones sociales se construyen por medio de reglas y la estructura de las instituciones humanas es una estructura de reglas constitutivas (Searle, 1997:140). Por ello están en la base de los hechos sociales: además de las reglas constitutivas del sistema de la lengua, sistema de posibilidades, hay otras reglas que restringen o regulan los usos de la misma. Estas normas son similares a las que encontramos, por ejemplo, en el deporte, cuando se restringe el juego de fútbol prohibiendo usar las manos. Consideramos que algunos usos de lenguaje no son correctos, por ejemplo, en español no se puede decir cabo como el presente de la primera persona del verbo caber, a pesar de que el presente del verbo tener es tengo. Esto es la norma, cuyo origen está en la sociedad, no en el sistema lingüístico ${ }^{2}$. Hemos aprendido que no podemos abordar a alguien sin preceder nuestro encuentro de un saludo, un acto que no lleva en sí mismo ningún significado referencial sino meramente interpersonal. El saludo no da ninguna información objetiva pero sí de índole social: la ausencia de saludo, por ejemplo, puede indicar o bien una desaveniencia, o bien una falta de educación.

En el caso de la cortesía, se trata de un conjunto de normas que se valen generalmente del lenguaje, pero que tienen como objeto la sociedad; no así las normas del lenguaje que tienen como objeto el lenguaje mismo. Como las normas del lenguaje, son abstractas y no cuantificables. Para ver esto más claramente recordemos brevemente la tripartición del lenguaje en sistema, norma y habla (cf. Coseriu, 1967; Lara, 1976) o en los términos de Hjelmslev, forma, forma material y uso (cf. Hjelmslev, 1972). El sistema lingüístico está íntimamente ligado a lo social, pero no está "conta-

2 El trabajo de Luis Fernando Lara (1976) es un excelente estudio sobre este tema. 
minado" de lo social. Podemos llegar a un alto grado de abstracción al imaginarnos un sistema desligado de los hechos sociales cotidianos, de las luchas entre grupos vecinos, entre partidos políticos, entre hombres y mujeres, grupos étnicos y religiosos; pero ésto no niega la naturaleza social del lenguaje: solo desligamos del sistema del quehacer diario para facilitar el análisis: es lo que Hjelmslev llama la forma pura (Hjemslev, 1972: 94, en Lara, 1976: 38).

Así también podemos comparar la norma lingüística con el concepto de forma material de Hjelmslev, "contaminado" de alguna forma con lo social; una especie de limbo cristiano en comparación con la pureza celestial de la forma pura. De la misma manera como el sistema no se identifica con el uso, por ser abstracto, tampoco lo hace la norma, que también lo es. La norma no es, necesariamente, lo más frecuente; por ello tampoco puede estudiarse con métodos cuantitativos, estadísticos, o probabilísticos; en cambio el uso promedio es lo que podríamos llamar el estándar. El estándar se obtiene a partir del uso de todo el mundo, mientras que para llegar a la norma hay que hacer un salto de valor. El uso sí puede medirse por la frecuencia de aparición de los fenómenos y aún las predicciones de su producción, que se logran a través de los análisis probabilísticos, pero el uso o el habla corresponden a otro nivel que no es abstracto, sino concreto. Esta es la razón, como veremos más adelante, por la que, para estudiar la cortesía como sistema de normas, no usamos métodos cuantitativos.

\subsection{Cortesía y gramática}

En relación con las normas lingüísticas, Barros (1997) propone la existencia de un discurso normativo que clasifica los hechos lingüísticos normativos en buenos, correctos, errados, bellos, etc. Este discurso remite a un aparato de referencia formado por los usuarios de prestigio y a los agentes codificadores, como academias, gramáticas y diccionarios y la difusión de esta norma, así como su imposición se dan a través de otras agencias como la escuela, las publicaciones o la administración pública (Barros, 1997).

La norma lingüística modelo, en lo que respecta al lenguaje, se genera cuando hay una valoración, por parte de los hablantes, de los productos 
lingüísticos anteriores (cf. Lara, 1976: 115)3. Lo que llamamos la norma social o la norma lingüística está formada por reglas ${ }^{4}$ que indican lo que una sociedad, un grupo de personas considera correcto; lo demás es lo incorrecto, lo que está fuera de la norma. Bello, (1972: 15) por ejemplo, consagra en su gramática, publicada por primera vez en 1847, el "buen uso, que es el de la gente educada”, el uso de los clásicos y no por último lo que él mismo considera de buen gusto. Considera feo al voseo del sur del continente y cree que por eso debe desterrarse del uso de los americanos (cf. Moré: 1999).

La norma parecería ser estar basada en un sistema de creencias, una ideología que convierte sus pautas sociales en pautas naturales, ocultando el origen la valoración que lleva a cabo; Fairclough (1992) llama esto la naturalización de las prácticas ideológicas. Por esta razón se clasifican los hechos de lenguaje con base a categorías éticas y estéticas a partir de criterios que no son lingüísticos y se opone así de un lado el uso bueno (correcto) al malo (incorrecto) y por el otro lado, lo bello o lo bueno del lenguaje. Ciertos usos pasan a ser naturalmente buenos y bellos, disimulando las relaciones de clase o de instrucción (Barros, 1997:34). Cortesía y gramática pertenecen ambas a los terrenos que se vuelven normas en la sociedad y en la lengua. La cortesía es un sistema de normas de comportamiento en sociedad y está íntimamente ligada al uso verbal, dado que las relaciones sociales se dan, en una gran parte, a través del lenguaje. La gramática también se somete a unas normas depuradoras que tienen su origen en las preferencias sociales 5 .

En cuanto a la cortesía, podemos trazar un paralelo con las ideas anteriormente expuestas. Si las gramáticas fijan las reglas de los idiomas, hay también un discurso de que fija las normas de la cortesía, hablándose también de lo bueno y lo malo, de lo bello y lo feo en las costumbres. También remite, este discurso, a un aparato de referencia, representado por la gente bien educada y las gramáticas de la cortesía, los manuales de urbanidad. Así también, esta norma se difunde a través de la escuela y los medios de comunicación.

\footnotetext{
3 Hay una distinción aristotélica entre praxis y poeisis, acción verbal frente a la dirección controlada de la acción verbal, de acuerdo con un sentido de la finalidad.

4 Para Lara (1976) son regulativas. En la teoría del Análisis Crítico del Discurso, cf. Fairclough (1992) podría considerarse que son constitutivas de la sociedad.

5 Es en este sentido que González Stephan (1998) considera las prácticas depuradoras en la sociedad y en el lenguaje como una prolongación de los procedimientos de higiene.
} 
En Venezuela se conocen una serie de manuales de cortesía ${ }^{6}$ y hasta el día de hoy aparecen manuales nuevos, como el de Guevara (1998) publicado recientemente por la editorial de uno de los dos diarios de mayor circulación en el país. Asimismo, las publicaciones dedicadas a la mujer son testigos del afán por difundir esas normas. La prensa merideña del siglo XIX abunda en estos escritos y todavía se encuentran secciones de urbanidad en la prensa escrita y televisiva.

El discurso de la norma al que aludíamos anteriormente puede verse en los acuerdos tácitos que los hablantes parecen tener al respecto. Esto ha sido estudiado, desde el punto de vista lingüístico, por varios autores. Por ejemplo, las normas de la conversación han sido objeto de amplias discusiones. Grice (1975) postula un sistema de principios y máximas con un principio de cooperación que él tiene como universal: adapta tus contribuciones conversacionales a la indole y al objetivo del intercambio verbal en que participas"; de este principio, categoría fundamental e irreductible, se derivan las máximas, que representan normas específicas.

Lo interesante de la teoría griceana reside más en el incumplimiento que en el cumplimiento de este sistema normativo. Así, cuando el hablante incumple las cuatro máximas griceanas de cantidad, calidad, relación y manera, se producen las implicaturas, que son significativas porque los hablantes reciben información de esos incumplimientos, al suponer que son intencionales. Así, el cumplimiento de las máximas conversacionales sería un problema para la vida en sociedad, precisamente, porque ellas están reñidas con la cortesía por las tensiones que podría producir, ya que están más orientadas hacia la referencia que hacia lo interpersonal ${ }^{7}$.

6 Entre ellos, los artículos en revistas como La Guirnalda, y Progreso y Cultura, dedicadas a la mujer como guía de la familia y base de la crianza de los hijos. Pueden clasificarse estas obras según el campo que enfatizan, según Sirola 2000) en obras religiosas de moral y de crianza, como las Lecciones de buena crianza, moral y mundo de Feliciano Montenegro y Colón de 1941, y las obras de Francisco González Guinand y Laureano Villanueva; obras de modales, cortesía y etiqueta, como las de Manuel Antonio Carreño, Enrique Campano, Marisela Guerra, Tania Rey Griman, Eleazar Aguilar y Nelson Ramos Castro y obras sobre etiqueta y protocolo de Cleidy Palomo, Blas Humberto Lemo, Manuel Acosta Rico, Julio de la Canal, Abundio Andrade. Hay incluso una obra dirigida a la escuela básica, titulada Qué rápido aprendo urbanidad y buenas costumbres, de Nelson Ramos Castro, de 1998 (Sirola, 2000).

7 Sin embargo, Carreño no deja de lado la referencia a la lógica en su Manual, y prescribe en su capítulo sobre las condiciones físicas de la conversación, 1, lo siguiente: "El razonamiento debe ser claro, inteligible y expresivo; coordinando las ideas de manera que la proposición preceda a la 
Otros investigadores postularon para la cortesía sistemas de máximas como complemento de las de Grice. Según Lakoff (1993 en Haverkate, 1994:6), por ejemplo, las estrategias verbales de las que se vale el hablante cortés son tres: No impongas tu voluntad al interlocutor; Indica opciones y Haz que tu interlocutor se sienta bien; sé amable. El modelo de Leech (1983) sugiere que, además de las máximas de Grice, debe haber un Principio de Cortesía con máximas de tacto, generosidad, aprobación, modestia, etc. Este Principio de Cortesía explica por qué, a pesar de las máximas de calidad y cantidad, la gente dice apropiadamente cosas que son falsas o poco informativas; como puede verse, estas máximas no se relacionan directamente con el lenguaje sino con el comportamiento social. Así, la teoría de Brown y Levinson (1987) supone que las máximas griceanas son de índole diversa las de cortesía, de modo que una respuesta parcial, por ejemplo, no rompe con la máxima de cantidad, sino que entra en otra esfera de la comunicación. En esta línea del estudio de la cortesía como estrategia performativa está centrado el trabajo de Haverkate (1997), un completo estudio sobre este tema en lengua española.

En Venezuela, el tema de la cortesía se ha vinculado con la moralidad y las buenas costumbres, también dentro de un marco religioso, como se muestra en la serie de manuales publicados en el país, especialmente en el de Carreño, donde los primeros capítulos se dedican a los deberes para con Dios, la sociedad, nuestros padres, la patria y nuestros semejantes (cf. Carreño, 1999). Además, se le aplican categorías estéticas y se relaciona con la higiene, de manera que también en Carreño hay capítulos vinculados a este tema. La naturalización del discurso de la cortesía también se encuentra en la conversación, por ejemplo, cuando Carreño pide - en genera 1 - para la conducta en sociedad, benevolencia, afabilidad y dulzura (Carreño, 1999: 176, § 4, 6).

consecuencia, y que ésta se deduzca fácil y naturalmente de aquélla; empleando para cada idea las palabras que la representen con mayor propiedad y exactitud; evitando comparaciones inoportunas e inadecuadas; eslabonando los pensamientos de manera que todos sean entre sí análogos y coherentes; huyendo de digresiones largas o que no sean indispensables para la mejor inteligencia de lo que hablamos; y finalmente, limitando el discurso a aquella extensión que sea absolutamente necesaria, según la entidad de cada materia, a fin de no incurrir nunca en la difusión, que lo oscurece y enerva, y lo despoja al mismo tiempo de interés y atractivo" (Carreño, 1999:185). Lo citamos, porque es sorprendente la claridad con la que este autor se adelanta a la discusión de la Pragmática moderna. 
En relación con su difusión por la escuela, recordamos que el Manual de Carreño lo declaró el Congreso Nacional en 1855 texto indispensable para la educación y formación de los venezolanos y es ampliamente conocido en toda América Latina: la edición de 1999, por ejemplo, es colombiana. El Manual se erige en norma nacional, sancionada por el Congreso de la República como texto para la enseñanza en 1853 (cf. Sirola, 2000). Todavía hoy, hay materias, en la escuela venezolana, relacionadas con el tema de la cortesía.

\section{Reparaciones y evasiones}

Los errores y las correcciones del lenguaje han sido tratados de las más diversas formas, en los estudios lingüísticos. Chomsky señala los falsos arranques, desviación de las normas y los cambios de plan como propios de la actuación, del uso real del lenguaje en situaciones concretas, que sólo idealizándose podría reflejar la competencia del hablante-oyente ideal: "A record of natural speech will show numerous false starts, deviations from rules, changes of plan in mid-course, and so on" (Chomsky, 1965:4).

Para nosotros, esas reparaciones son más que borrón y cuenta nueva, porque podemos percatarnos a través de ellas, de cuál es la idea de lengua ideal que los hablantes persiguen; una gramática de los errores que cometen los hablantes nos llevaría a la gramática de la norma, o sea del ideal de lenguaje. Asimismo, si hacemos la sociolingüística de la sociedad y no la sociolingüística del lenguaje ${ }^{8}$, podemos estudiar la norma social, en nuestro caso, la cortesía verbal, a través de estas "imperfecciones", esas mismas reformulaciones, falsos arranques y cambios de plan.

Barros (1997), siguiendo a Sacks, Schegloff y Jefferson (1974), quienes proponen el clásico modelo de la toma de turnos y sus reparaciones, estudia las reparaciones que hacen los hablantes en la llamada norma culta, en el Corpus de São Paulo. Para esta autora, la reparación debe entenderse como la corrección de las violaciones de las reglas conversacionales. El modo, por lo tanto, como el hablante infringe las reglas de la conversación o corrige las infracciones propias o de su interlocutor es una de las formas de la construcción del papel social de hablante culto (cf. Barros, 1997:36). Para

8 Las expresiones provienen de los títulos de Fasold (1984) y (1990). 
Barros (1997: 41) son pocas las reparaciones que los hablantes se permiten, y las hacen en condiciones extremas y se dan como sustituciones de términos en el plano estilístico, superposiciones de voces en la disputa por el turno y en los procedimientos de reparación de la imagen.

\section{Metodología}

Este trabajo se basa en las reparaciones que hacen los hablantes del corpus sociolingüístico de Mérida, recogido como El Habla de Mérida (Domínguez y Mora, 1998). Estos materiales son el resultado de la transcripción de cuarenta horas de grabación de entrevistas semielicitadas con ochenta hablantes merideños nativos, de media hora cada una de estas sesiones. Los hablantes, o bien nacieron en la ciudad de Mérida, o en el Estado Mérida (Venezuela) y han vivido, todos ellos, gran parte de su vida en la ciudad. Los encuestadores no tenían trato familiar con los entrevistados, de modo que no hay, en el corpus, conversaciones en las que la cercanía dificulte la recuperación de la referencia a los temas tratados en las entrevistas (cf. Domínguez, 1996). Las intervenciones de los entrevistadores son limitadas, de acuerdo con las instrucciones que recibieron. Con el fin de evitar que los hablantes prestaran atención al lenguaje, se les dijo que el interés de las grabaciones era recopilar información sobre las tradiciones, las costumbres y los valores regionales (cf. Domínguez y Mora, 1998, Domínguez, 1996).

La edición de El Habla de Mérida (Domínguez y Mora, 1998), con la que trabajamos, recoge las entrevistas de veinticuatro de los hablantes del corpus general: 12 hombres y 12 mujeres, seis hablantes por grupo de edad y ocho hablantes del nivel alto, ocho del nivel medio y ocho del nivel bajo?.

Para estudiar las reparaciones en estos materiales, aislamos todas las instancias en las cuales los hablantes se corregían, o corregían a sus interlocutores, en este caso, los encuestadores del corpus. Sin embargo, no

9 El corpus, en su totalidad, está repartido en 40 hombres y 40 mujeres distribuidos en cuatro grupos generacionales (A: 14-29 años; B: 30-45 años; C: 46-60 años; D: 61 años o más). Los hablantes se distribuyeron en cinco grupos socioeconómicos, de 16 hablantes cada uno, identificados como 1: alto; 2: medio-alto; 3: medio; 4: medio-bajo; 5: bajo. 
es este un trabajo cuantitativo: la norma social relacionada con el lenguaje no puede estudiarse como el uso lingüístico. Para estudiar éste último pueden contarse las instancias de la aparición de un fenómeno, por ejemplo, el porcentaje de aspiración del fonema /s/ en el habla de Caracas. La norma no se identifica con el uso diario y por ello no puede estudiarse a partir de métodos cuantitativos, estadísticos, ni probabilísticos; la norma no necesariamente es lo más frecuente, en cambio el uso promedio es lo que podríamos llamar el estándar. El estándar se obtiene a partir del uso de todo el mundo, mientras que para llegar a la norma hay que hacer un salto de valor y llevar a cabo un proceso de codificación (cf. Lara, 1976).

$\mathrm{Al}$ tener aislados los casos de reparaciones y evasiones, que nos llevaban a las posibles infracciones de las normas que se habían producido, inferimos - a partir de cada caso - cuál era la norma que se había quebrado. Obviamente que esto se da a partir de un proceso de interpretación de nuestra parte que puede resultar subjetivo. Para paliar esta deficiencia hemos comparado nuestros resultados con otras instancias, como por ejemplo el Manual de Carreño (1999), un tratado de cortesía que recoge las normas que han regido a la sociedad venezolana durante el último siglo. No por último, se hicieron también comparaciones con los resultados de Barros (1977) que hace un estudio similar en el corpus sociolingüístico de São Paulo.

El presente estudio es de orden cualitativo: el investigador trata de comprender el sistema de normas que está detrás del uso lingüístico, en este caso, referido a lo social. Dado que nuestro interés está en el estudio de la norma social, nos detendremos sobre todo en las reparaciones de la norma que se relacionan con este ámbito. Por ello nos proponemos, en esta sección, analizar en los materiales de habla recogidos en Mérida las instancias donde se muestran las normas de cortesía. Analizamos, en la primera parte y de acuerdo con Barros (1977), los procedimientos de reparación de la imagen.

Dejamos de lado las reformulaciones relacionadas con la gramática ${ }^{10}$. Tampoco nos detenemos en las infracciones a los cambios de turno, que pertenecen a los procedimientos de cohesión del género "conversación"11;

10 Son el objeto de un trabajo de Carmen Luisa Domínguez (en prensa)

11 Este tipo de corrección en la toma de turnos ha sido ampliamente estudiado por Barros (1993) 
y descartamos también las reparaciones que se dan sin cortesía. Además de las reparaciones, incorporamos en la segunda parte del trabajo otras instancias, porque nos dimos cuenta de que había en estos textos otras modalidades para la construcción de la imagen del hablante cortés, como son la búsqueda del consenso, los halagos, y el uso de las llamadas "fórmulas de cortesía”.

Como resultado de nuestro estudio, obtuvimos el conjunto de normas que suponemos se infringieron en el corpus y que los hablantes, conscientes de sus infracciones, intentaron corregir. Ello nos da una idea, por una parte, del conjunto de normas sociales que rige el lenguaje recogido en $E l$ Habla de Mérida. Por la otra parte, nos indica cuáles son las estrategias que los hablantes utilizan para lograr su propósito y en tercer lugar, nos ofrece la imagen del ideal de hablante manejada por nuestros encuestados. Esta visión debería confrontarse claro está, en otros trabajos sobre el tema de la cortesía, en observaciones de campo diferentes del Habla de Mérida (Domínguez y Mora, 1998), que nos ha servido de base para nuestro estudio.

\section{Análisis: las estrategias de reparación y evasión}

Veamos, en primer lugar, cómo se dan estas reparaciones y cuáles son las estrategias que usan los hablantes para corregir lo que vienen haciendo para seguir la norma social. Encontramos reparaciones del propio discurso y del discurso del otro, con atenuaciones en los casos que estudiamos; los hablantes dudan, se detienen, cambian términos, omiten palabras, niegan e introducen marcadores de interacción para proteger la armonía de la conversación. Así se cumplen, entre los hablantes merideños, parte de las características que le atribuye Barros (1997) a la conversación culta, sobre todo en lo referido al disimulo de los procesos de reparación y correcciones del otro por medio de la atenuación. En el caso de Mérida, algunos de ellos son los diminutivos, la negación, los marcadores de interacción, las pausas, la sustitución de términos y el uso de eufemismos.

\subsubsection{Sustitución de un término por otro}

Carreño recomendaba, en su Manual, la llaneza y sencillez en el estilo, y consideraba "ridículo el excesivo esmero en la elección de las palabras y 
frases (Carreño, 1999:186). Así, encontramos también en el corpus las reparaciones del registro, cuando el hablante sustituye lo que acaba de decir por otra expresión menos formal que parece más adecuada a la situación como en el ejemplo (1), donde se repite padres en vez de progenitores. En (2) se prefiere el término muchachona, más común que gïina, quizás para salvar al oyente de un posible desconocimiento del término. En (3) el hablante establece una sinonimia que no es precisa, porque un popsicle es un helado de palito, y un raspado es 'hielo molido cubierto de jarabe'; esto muestra cómo la inseguridad que procede de no establecer la referencia, parece obligar al hablante a lograr que el oyente identifique cualquier cosa.

(1) actualmente son muchos...los niños que vienen de hogares....que no tienen... que no tienen ...progenitores, no tienen padres...(MDD1FA)

(2) yo...era una güina todavía, pero me dio... los tifus, era muchachona todavía (MDD5FB).

(3) ...y de ahí sacaban los... los hela... los popcicles [posícles]... o sea los raspados. (MDD5MA).

Se sustituyen algunas expresiones por otras menos marcadas socialmente; por ejemplo, tirar piedras es socialmente reprobable y se prefiere protestar, en (4); terrible se sustituye por un poco tremendo, atenuando la expresión en (5).

(4) Inv.: ...pero a tí te gusta tirar piedras entonces.

Hab.: No, tirar piedras no sino... ir a ver... y ... a protestar claro, pero no estar tirando piedras.

(MDA5FA)

(5) Inv?: Es terrible como su papá, habíamos dicho anteriormente (hablando del hijo de la encuestada)

Hab.: No..bueno, sí es un poco tremendo...

(MDA5MA)

\subsubsection{Omisiones y eufemismos}

Hay cosas que no se dicen en sociedad y los hablantes las dicen con eufemismos, como en (6) donde la hablante no se permite calificar el tipo de vida de la mujer de la que habla; o las dicen negando que lo hacen, como en el (7) donde el sin decir, le permite al hablante decir justamente lo que quiere. También pueden dudar en decirlas, con el marcador bueno y varios falsos arranques como en (8). 
(6) ¿no han oído ustedes hablar de...de una...una mujer así de vida...más o menos...no correcta, no? (MDD3FB)

(7) ..cuando salió...cuando ocupó su sede...sin decir que fue sacada o botada, ino?...(MDD1MB)

(8) Inv. ¿sí deja bastante?

Hab.: Sí deja bastante, bueno, lo...pa...lo...lo suficiente, no así mucho como para darle...o sea, vive uno...modestamente, modestamente no, pero...más o menos sí da para vivir...sobreviviendo, como dicen. (MDA5FA)

\subsubsection{La atenuación}

La atenuación ${ }^{12}$ pretende restarle importancia a lo dicho, a través de diversos procedimientos. Uno de ellos puede ser a través de la pausa, que señala quizás inseguridad o duda en lo que se dice; ejemplo de ello es (9) donde se introduce una pausa antes de tocar un tema prohibido socialmente. Se puede atenuar también a través de la negación, como en (10) o con el uso de diminutivos, como en (11):

(9) que yo creo que sí es una enfermedad ino? que todavía la tengo, que yo no puedo aguantar... las ganas de orinar... (MDA5FA)

(10) ... yo no sería tan fea cuando estaba más muchacha...(MDD5FB)

(11) ..y tercer año lo estudié en La Inmaculada, allá éramos un poquito más traviesas (MDA3FA)

Las anteriores atenuaciones se dan en el propio discurso, pero también se producen cuando un participante en la conversación no acepta lo dicho por el otro. Así en el ejemplo (12) la hablante no está de acuerdo con la interlocutora y atenúa con locuciones como si supieras, para no negar rotundamente. En (13) se atenúa asimismo con marcadores de interacción como ¿tú sabes? y supuestamente y en (14) con bueno (cf. Domínguez y Álvarez, en prensa).

(12) Inv: Como no te dé por agarrar una carpa y llevártelo para el medio de un parque y ahí está la naturaleza en pleno...

Hab.: No, si supieras que le... a él también le gusta mucho la naturaleza... (MDA3FA)

12 El tema ha sido estudiado en español por Briz (1994) y Puga (1997) 
(13) Inv.: Hablan italiano

Hab.: En sus casas hablan es dialecto. Ah... pero a mí... ¿tú sabes que a mí la gente no me encuentra acento? supuestamente.

(MDB3MA)

(14) Inv.: Perfecto. Mira, este...esos muebles son bellos, e...¿no...no los diseñas tú?, ¿̇me dijiste que eran de...?

Hab.: No, bueno, lo de hierro es de una artista...especializada en hierro forjado...

(MDD1FB)

Negar abiertamente lo dicho por el interlocutor podría causar uno de esos "incidentes" de los que habla Goffmann (1967); una de las maneras de atenuarlos es la risa. En (15) los hablantes contradicen a los investigadores, pero ríen para quitarle importancia a lo que dicen.

(15) Inv.: ¿verdad? Parece mentira porque supuestamente por aquí y que es muy sano, dicen ino?

Hab.: No, parece que no [[risas]]

(MDA5MA)

Se dan excusas pretendiendo no recordar o no conocer los hechos por no haber estado allí para evitar conflictos. En (16) se observa cómo el hablante afirma haber salido demasiado joven de su pueblo para evitar tener que aceptar la invitación del investigador a contar historias o a recordar peleas; esto lo hace sin decir, por supuesto, que se niega a responder a la invitación.

(16) Inv.: Mire ¿y usted recuerda alguna de esas historias bonitas de Chiguará? que haya habido alguna pelea por allá....

Hab.: Yo salí muy muchacho de Chiguará

(MDD3MA)

\subsection{Estrategias de consenso}

Pero además de evitar el conflicto, los hablantes dedican mucha energía a concertar acuerdos entre ellos, a cuidar su relación interpersonal y a manifestar la cercanía que van construyendo en la interacción, paso a paso. Se incluyen estos acuerdos en este trabajo, porque pensamos que hay un esfuerzo consciente de los hablantes, tanto como lo hay en las reparaciones, para lograr un ideal que es el de la armonía, que prevalece en las normas de conversación. Carreño habla, recalcamos, del "espíritu de benevolencia 
y consideración" y de "la afabilidad y dulzura" que deben imperar en estos encuentros (Carreño, 1999:176). Por esta razón incluimos los acuerdos entre los procedimientos que los hablantes utilizan en su sistema de cortesía.

Los procedimientos para marcar esta armonía son varios, por ejemplo, marcando el acuerdo como en (17); con marcadores de interacción como ¿tú ves? (18); simulando que les han quitado el pensamiento que en realidad era suyo (19); completando las oraciones del interlocutor (20) o contrapunteando en el mismo sentido para lograr abiertamente la comunión emocional con el otro. Llamamos contrapunteo a la manera cómo una hablante toma el tema del otro y lo desarrolla.

(17) Hab.: ¿De verdad que tengo razón? Inv.: Sí sí, por supuesto que sí...

Hab.: ¿Verdad que es auténtico yo lo que le estoy diciendo?

Inv.: Cien por ciento, sí, pero sólo después de que uno ha estudiado eso... (MDD1FA)

(18) Hab.: ...me siento mal ¿qué voy a hacer a casa yo ahora? ¿con quién voy a hablar?...¿tú ves? (MDD3MA)

(19) Inv.: La historia

Hab.:...me lo quitaste, la reseña histórica...

(MDD1MB)

(20) Hab.: Porque no me voy a esperar...además la gente que me compra a mí es gente muy...de muy...

Inv.: Sobria.

Hab.: Muy sobria, de muy buen...

Inv.: Gusto

(MDB1FB)

(21) Hab.: Y todavía, yo le digo a M., todavía, yo veo por ahí...al tercio aquel y uh...que Dios me perdone, Santísima Virgen, pero es que a mí se me retuerce...y él a mí (no se entiende), ay, yo lo miro que...ni lo hab...yo no le hablo.

Inv.: No, y qué le va a estar hablando uno a ese tipo. hab.: No, pero él sí, él sí, ay, a saludarlo a uno, y yo no, yo le volteo la cara y no lo saludo, que Dios me perdone chica, pero es que ése fue tan...canalla, tan malo, que uy...

Inv.: Tan muérgano.

hab.; Uy, que que Dios me perdone, pero es que ese bicho no tienen perdón de Dios, uy, uy, cómo sufrió M. con ese hombre [[suspiro]] y uno sí es bolsa...

En este mismo sentido, para crear consenso, hay repeticiones, una forma muy interesante de lograr acuerdos porque son icónicas: ambos 
piensan lo mismo y dicen lo mismo. Estas se dan de dos maneras, ya sea repitiendo la pregunta como en (22) o bien repitiendo la respuesta, como en (23). Véase lo interesante del ejemplo (24) con su patrón AB C AB y del ejemplo (25) donde el interlocutor parafrasea lo que dice el otro.

(22) Inv.: ¿tu padre es merideño?

Hab.: Mi padre es merideño...

(MDB1MA).

(23) Inv.: Es lo que más se vende

Hab.: Es lo que más...se vende

(MDA5MA)

(24) Hab.: ..y mi amigo y que llegaba y que "cuándo se va a casar?” y si no lo botaba para el coño. No....

Inv.: Para lo que le sirvió

Hab.: Para lo que le sirvió.

Inv.: No sirvió para nada.

Hab.: Sí, ¿para qué le sirvió?

Inv.: Necedad y ¿para qué le sirvió?

(MDB3FB).

(25) Inv.: Pero tú estás metida en alguna cuestión política y eso.

Hab.: No, guillo, no me gusta la política.

Inv.: No te gusta la política, o sea tú eres...

Hab.: Independiente.

Inv.: Independiente.

Hab.: No me gusta la política.

Inv.: pero sí te gusta reclamar tus derechos.

Hab.: Sí, mis derechos...mire...

(MDA5FA)

A lo largo de estas páginas hemos revisado dos procedimientos básicos que implican la atención consciente del hablante, las reformulaciones y los acuerdos, que refieren a la existencia de un sistema de normas obligatorias para la consecución de dos fines, la armonía entre los hablantes y la evasión del conflicto. Reparación y evasión son dos rituales nucleares para la construcción de las relaciones sociales. Todas estas normas que refieren a lo permitido y a lo prohibido permiten incursionar en lo que sería la gramática de las relaciones entre las personas, siempre desde un sistema básico, como es el lenguaje. Estas normas están subordinadas a la construcción de un ideal de hablante, por no decir a un ideal de persona. 


\section{La cortesía como imagen}

Quienes fundamentan la cortesía en el concepto de imagen se basan en el hecho de que los hablantes adultos de una sociedad tienen una imagen o rostro y saben que los demás también la tienen. La imagen se compone, en la teoría de Goffmann (1967), de una serie de deseos que se satisfacen sólamente a través de las acciones de otros, incluyendo la expresión de estos deseos. En la etimología inglesa, la noción de imagen se relaciona con el hecho de que ser humillado es perder el rostro. La imagen es vulnerable y es allí precisamente, en la necesidad de mantenerla mutuamente, donde se fundamenta el esfuerzo de cooperación que se observa entre ellos (cf. Brown y Levinson 1987: 61).

La imagen es de naturaleza discursiva y su construcción se lleva a cabo a través del lenguaje. Para Goffman la imagen es un guión (line) que debe ser representado, o actuado: "un modelo de actos verbales y no verbales a través de los cuales expresa su visión de la situación y, a través de ella, su evaluación de los participantes, y especialmente de sí mismo" (Goffman, $1967: 5)^{13}$. El rostro es entonces un valor social positivo que la persona reclama para sí, a través del guión que otros han asumido durante un contacto particular (Goffman, 1967:5).

La identidad como concepto se opone al de alteridad: el uno no puede definirse sin el otro; así también, en la teoría de Goffmann, la imagen tiene dos aspectos: la imagen negativo que es el deseo de cada uno de no ser invadido en su espacio personal, de no ser agredido, de que no se lesione la libertad de acción de cada quien y la imagen positiva que es el deseo de cada miembro de la sociedad de ser apreciado por los demás y de que se cumplan sus deseos personales (Goffman, 1967; Brown y Levinson 1987; Haverkate, 1994).

La imagen es vulnerable y su violación se sanciona con un conflicto, o sea un tipo de interacción marcada, valorada negativamente por sí misma y que está en contra de las normas generalmente aceptadas (Haverkate, 1994:19). Es aquí donde la cortesía juega un papel, porque este sistema de reglas trata de evitar, precisamente, la violación de la imagen personal. La vida en sociedad es un constante peligro para la individualidad, y de ahí la necesidad de la cortesía; por ello esa especie de pacto social de no agresión.

13 Todas las traducciones del texto son nuestras. 
Los "incidentes" son incompatibles con las normas sociales y se consideran amenazas para la imagen y crean un estado de "desequilibro ritual o desgracia" que obliga a su pronta reparación (Goffmann, 1967: 19). A través de estas reparaciones, el actor muestra que tanto él mismo como los demás son dignos de respeto; la cortesía pone a salvo, de esta manera, o bien los límites del campo de acción de cada uno, o bien el deseo de cada quien de ser amado por los demás, es decir las imágenes positiva o negativa de la persona; se habla, en este sentido, de cortesía negativa o cortesía positiva.

Aún cuando indudablemente hay elementos universales en la cortesía - en muchos pueblos se saluda, se hacen visitas, se piden disculpas - es evidente que ella no se lleva a cabo de la misma manera en todas partes. Haverkate (1994) opina que en todas las culturas desempeñan un papel social ambos tipos de imagen, aunque la función e interpretación de las mismas pueda variar de una cultura a otra.

Sin embargo, hay diferencias entre las culturas que se originan en las normas sociales que rigen en ellas. Brown y Levinson (1987: 243) sostienen que las características de cada grupo se dan porque que las culturas difieren en lo que llaman el ethos, la calidad afectiva de la interacción de los miembros de una sociedad. De esta manera, el ethos de la interacción puede ser cálido, fluido y amable, o tieso y formal; o incluso pedante u hostil.

De este modo sucede que en algunas sociedades hay un mayor deseo por los actos para la satisfacción de la imagen positiva que en otras ${ }^{14}$; esta distribución parece darse también en cuanto a las divisiones sociales intraculturales de modo que, en sociedades más complejas, los grupos dominados y también las mayorías tienen culturas de cortesía positiva, mientras que los grupos dominantes tienen culturas de cortesía negativa; en última instancia la diferencia se basa en la estructura de la sociedad. La imagen negativa se fundamenta en una sociedad donde imperan las diferencias, la distancia, la asimetría y las imposiciones, mientras que la imagen positiva prevalece cuando se cultiva la cercanía, la solidaridad social y la reciprocidad (cf. Brown y Levinson, 1987:245).

14 Brown y Levinson (1987) diferencian así las sociedades americana e inglesa, en Venezuela distinguiríamos probablemente de este modo a los centrales de los andinos. 
Dicho esto, queremos revisar en este sentido las reparaciones, que operan con la finalidad de "deshacer entuertos" como diría Don Quijote, entuertos referidos a los rituales de interacción; son aquellas que Barros considera como procedimientos de reparación de la imagen (Barros, 1997:41). Lo veremos ahora según las dos caras de la imagen - y de la cortesía - la negativa o la defensa del territorio privado y la positiva, el cuidado de la apariencia propia y de los demás.

\subsection{La imagen positiva: ser amable}

Usemos siempre de palabras y frases de cumplido, de excusa o de agradecimiento, cuando preguntemos o pidamos algo, cuando nos importe y nos sea lícito contradecir a una persona, y cuando se nos diga alguna cosa que no sea agradable...(Carreño, 1999:191)

La imagen positiva, como vimos anteriormente, se fundamenta sobre el deseo de ser apreciado, amado, tomado en cuenta. La forma más sencilla de mostrar el rostro positivo, de ser amable y bien educado es a través del uso de fórmulas de cortesía. Se encontraron en el corpus muchas de éstas fórmulas. El hablante (MDB5MA), por ejemplo, dice gracias en seis oportunidades, una de ellas acompañada por un placer sí, gracias. En otra entrevista, el hablante (MDB1MA) dice un que Dios me le pague a usted. Hay largos intercambios de cumplidos, en saludos hacia otras personas; las disculpas como disculpa (MDD3MA), perdóname (MDD5MA), o que Dios lo oiga (MDC1MA), están a la orden del día y ocupan amplios segmentos de habla.

Los investigadores agradecen a los hablantes y no es raro que se pongan a la orden (26), repitan el saludo como en (27) o se disculpen (28). Asimismo, hablan cortésmente con otras personas, como en (29) donde se interpone la grabación de una conversación real que se llevó a cabo durante la conversación con el investigador; esto es importante porque muestra lo que sucede en la realidad, sin que esté marcado por la situación de entrevista; veamos:

(26) no, yo estoy a la orden cualquier cosa que... le pueda ser útil (MDA3MA)

(27) buenas tardes, ¿cómo está? siéntese, la señora, aquí, ¿cómo está? (MDD1MB). 
(28) ..y me dijo “ay, profesor, lo felicito, a usted lo nombró la Academia por unanimidad....usted me perdona, yo no pude ir porque...estaba malito, estaba ahí enfermo ¿usted ve? y no pude trasladarme allá, pero si yo hubiera estado en la reunión esa, voto por usted....(MDD1MB)

(29) Albarregas, buenos días, a la orden...no está ahorita hija...no señora...cómo no se....ah, perdón mija, él lo puede conseguir en el termina...sí señora él está trabajando allá hoy...okei, hasta luego (MDD3MA)

Los hablantes describen sus cualidades, aunque con atenuación. En el ejemplo (30), la hablante dice que ella fue bonita en su juventud (31), que hacía bien su trabajo (31) y que era hábil (32); pero como esto no debe decirse, porque no queda bien ensalzarse uno mismo, se hace con atenuaciones.

(30) Yo no sería tan fea cuando estaba más muchacha...(MDD5FB)

(31) y yo era una muchacha muy buena, sirviendo (MDD5FB)

(32) pero no era tan boba y entonces le dije "usted me tiene que dar plata...." (MDD5FB)

Contribuye asimismo a la construcción de una buena imagen el hecho de ser ahorrativo (33) o hablar un idioma sin acento (34); pero siempre hay que atenuar, como se hace en estos ejemplos con se lo digo buenamente, en el primero de los casos y la pregunta indirecta ¿tú sabes que....supuestamente?. Estas estrategias le permiten a los hablantes alabarse a sí mismos, algo que sería, de otra forma, inaceptable.

(33) ...yo...he sido muy económico...yo he sido muy económico...mire, se lo digo buenamente, yo hipotequé esto, para poder hacer la casita ... (MDD5MA).

(34) Inv.: Hablan italiano Hab.: En sus casas hablan es dialecto. Ah...pero a mí...¿tú sabes que a mí la gente no me encuentra acento? Supuestamente.

(MDB3MA)

La imagen puede también implicar cualidades que no son tan buenas, pero que los hablantes ensalzan; así por ejemplo ser tremendo o travieso parece formar parte de esas características que se convierten en deseables como en (35-36).

(35) ...sí yo era muy tremenda, yo me encaramaba en la finca, en los árboles...y después me tiraba y me rompía las piernas.... (MDA1FA) 
(36) ...y tercer año lo estudié en La Inmaculada, allá éramos un poquito más traviesas (MDA3FA)

El cuidado de la imagen, tanto la propia como la de los demás, no permite hablar de dinero, sobre todo cuando éste es escaso (37), ni mencionar la cultura, cuando no se tiene (38), ni regodearse en las enfermedades (39). El uso de la atenuación en estos casos nos indica que hay normas generales al respecto.

(37) Inv. ¿sí deja bastante?

Hab. Sí deja bastante, bueno, lo... pa ... lo ... lo suficiente, no así mucho como para darle...o sea, vive uno...modestamente, modestamente no, pero...más o menos sí da para vivir...sobreviviendo, como dicen. (MDA5FA)

(38) esa gente pues, como es una gente que...generalmente viene de...hogares donde los...muchos...de los padres son analfabetos, pues....(MDC3FA)

(39) que yo creo que sí es una enfermedad ¿no? que todavía la tengo, que yo no puedo aguantar...las ganas de orinar... (MDA5FA)

La necesidad de defender la imagen, aún en situaciones adversas, se observa en el ejemplo (40) donde vemos cómo el hablante previene un posible daño ante el otro por el hecho de no haber hecho estudios sistemáticos; por ello argumenta a su favor y, si bien concede que no ha estudiado, resalta su capacidad para sustituir esa falta con la virtud de "arrimarse a buen árbol".

(40) ....soy una persona que no tuve ni ni ni...una educación, de decir "yo tengo primer grado"

Inv.: Mjm.

Hab.: ...porque no lo tengo, pero... yo... hasta ahorita con mi experiencia y con... mi angustia de... de saber lo que... no pude aprender, en mi juventud... pues... siempre he obtenido... mucha e... sabiduría... porque... he sido la persona que me ha gustado... lo que llamamos nosotros en criollo "arrimarme al árbol que da la buena sombra”...(MDC3MA)

\subsection{La imagen negativa: ser respetuoso}

La conversación debe estar siempre animada de un espíritu de benevolencia y consideración que se extienda, no sólo a todos los circunstantes, sino también a los que no se hallan presentes..." (Carreño, 1999:176).

Al lado de la imagen positiva también existe el otro lado, el de la alteridad: la defensa del territorio personal y el respeto por el otro. Este 
suele ser el tipo de cortesía del que se habla en los manuales. De su cuidado en las entrevistas, encontramos los siguientes ejemplos:

d) Cuando los hablantes evitan decir aquellas cosas que no se deben decir socialmente, ese no decir produce una implicatura, de modo que la misma duda le indica al otro que algo pasa; esto lo vimos anteriormente en el ejemplo (6) y entendemos que es norma no dañar la imagen ajena y no inmiscuirse en la vida íntima o privada.

Con este tipo de expresiones, los hablantes muestran su conciencia del espacio social, una especie de aura que no debe traspasarse: a través de esta actitud de respeto los hablantes muestran su conocimiento de las normas de acatamiento o de contención que se hacen por cortesía; como decíamos al principio, de moderación. Los incidentes se producen sobre todo cuando se corrige al otro y hay instancias en que los hablantes no dudan en hacerlo, en este caso a los investigadores, cuando éstos dicen algo que no está permitido, y que se siente como una intromisión, como vimos en el ejemplo (4) donde el hablante se defiende de la imputación de que el es un revoltoso.

En (41) la hablante, una diseñadora de modas, hablando de gente que no tiene buen gusto, debe buscar un término más leve que el usado por la investigadora, desecharlas. Ella sabe que las personas no se desechan, porque eso sería contra la moral, sabe también que puede evitar el contacto con gente que no tiene su nivel de distinción pero que, como persona cortés, debe hacerlo sutilmente, veamos:

(41) Hab:...a mí no me interesa ese tipo de personas, entonces, por lo general, trato de decepcio...de no..

Inv: desecharlas

Hab.:...de romper ese contacto con esas personas...

(MDB1FB)

Hablar negativamente sobre los diseños de una rival sería invadir su espacio social, por eso esta hablante atenúa fuertemente, como se ve en (42) con los procedimientos que vimos en la sección anterior (pausas, risas y evasiones) para no tener que decir que sus diseños no son de su gusto porque no son naturales. 
(42) Inv: Bueno, pero en lo poquito que viste, de cuando ella era estudiante... Hab.: No...no sé, no me acuerdo muy bien de lo...de los diseños que ella hizo, no me acuerdo, ella hizo, bueno...no tenía mucho...mucho empeño con la naturaleza...

Inv. ¿De verdad?

Hab.:..de lo que me acuerdo, no tenía mucho empeño en la naturaleza como yo [[risas]].

Inv.: A ti sí te gusta.

Los hablantes corrigen a sus interlocutores cuando éstos pretenden hacer afirmaciones que implican una invasión del espacio propio. Sin embargo, como son hablantes respetuosos, lo hacen con firmeza, pero con moderación. Aceptar la violencia, o la desmesura como en el ejemplo (43) es inadmisible; puede moderarse la afirmación diciendo que el niño es un poco tremendo. Lo mismo sucede con la derrota en un examen; a nadie le gusta admitir que ha sido suspendido en los estudios (44), por lo que el hablante divaga y falla finalmente porque no encuentra la expresión exacta y dice se me había perdido ya, lo cual es incorrecto, porque las materias no se "pierden” en el español hablado en Mérida.

(43) Inv: Es terrible como su papá, habíamos dicho anteriormente (hablando del hijo de la encuestada)

Hab.: No..bueno, sí es un poco tremendo...

(MDA5MA)

(44) Inv.: Estabas...ya pelado, ya te habían raspado.

Hab.: Se me había perdido ya.

(MDA5MA)

Tampoco contribuye a la buena imagen admitir que se diga que el marido propio es violento, aunque sea celoso. La pregunta de la investigadora en (45) es inadmisible, porque el estilo de la entrevista es semiformal y porque es una intromisión en el territorio de la hablante. Ella puede hablar de los celos de su marido, pero no su interlocutora:

(45) Inv.: ¿Lo muele a palos?

Hab.: ¿Ah?

Inv.: ¿Le cae a palos al tipo?

Hab.: No, no le cae a palos sino que...por lo menos Ch. es una persona que es muy celosa, demasiado celosa....

(MDA1FA) 
El ejemplo (46) habla sobre los gustos del entrevistado y evidentemente la manera de hacer la pregunta ¿pero te gusta eso? es demasiado directa e invasora; lo que genera la réplica No bueno, me gusta curar los perros porque sencillamente..me gusta ver..verlos mejor ¿no? que podría parafrasearse como, 'lo hago porque es necesario, porque soy una buena persona y me gusta ver saludables a mis animales'. En (47) la investigadora insiste en atribuirle cualidades al niño del que se habla que evidentemente no tiene, lo cual hace que la hablante introduzca una pausa de atenuación para poder seguir insistiendo: no es travieso sino muy tímido.

(46) Inv: ¿pero te gusta eso? (hacer el papel de veterinario en la casa)

Hab.: No bueno, me gusta curar los perros porque sencillamente... me gusta ver... verlos mejor ino? (MDA1MB)

(47) Hab.: Pues...muy tremendo pues, como todos los niños.

Inv. Y habla bastante iverdad?

Hab.: No, él casi no habla, es muy tímido.

Inv.: ¿Sí? ¿y travieso?

Hab.: Travieso sí, pero ...muy tímido...

(MDA5FA)

El ejemplo que se muestra en (48) no puede calificarse sino como una terrible imprudencia de la investigadora, la cual logra remendar a duras penas porque contradice con su $A y$, qué ridículas, abiertamente la manera de pensar de la hablante sobre algo tan delicado como la moral y las buenas costumbres. La informante no se deja intimidar y procede diciendo: Que qué ridículas, vas a ver que la van a cerrar.

(48) Hab:...que ese es un centro de perdición, ahí lo que tú vas y ves... es puras niñas con los pelos... pegados, alborotados... y se ve... droga como nada en la ciudad... a mi hermanito le encanta ese sitio, yo en estos días le dije por lo menos "tú sabes que van a cerrar Tops, ¿no?”, porque las mamás de (...) están reuniendo firmas para que lo cierren...

Inv.: Ay, qué ridículas...

Hab.: Que qué ridículas, vas a ver que la van a cerrar... a esa discoteca le tiran muchos allanamientos, casi todas las noches, porque lo que van es puros menores de edad. Es horrible, es horrible, tú entras y desde que entras...es como si...mira yo he ido como tres veces y las tres veces que hemos ido hemos tenido un problema...

(MDA1FA) 
Igualmente agresiva es la serie de preguntas del ejemplo (49), cuyo tema es algo desagradable para cualquiera: la hablante no quiere recordar los castigos, y al decirlo, cambia el tema de la entrevista hacia las cosas agradables de su juventud.

(49) Inv.: ¿Y los castigos cómo eran? ¿cómo eran los castigos?

Hab.: Ay yo no recuerdo los castigos, por casualidad nos estábamos acordando anoche, allá con la hermana mía, que sacó mamá...unas cositas de bordados, y tejidos y eso...entonces sacó un tapetico que bordé yo en punto de cruz.. que lo enseñaban a uno a bordar y todo, que ahora no, nada de eso, yo aprendí a bordar punto de cruz en el colegio, tantas manualidades, a tejer, todo eso (MDC1FA).

Las reparaciones de la imagen que encontramos en el corpus llevan a postular, entre los hablantes de este corpus, una serie de normas que revelan el cuido soslayado y atenuado de la propia imagen positiva y a la vez la deferencia hacia el otro. Al mismo tiempo encontramos una fuerte defensa de la imagen negativa, propia y ajena, con los correspondientes ocultamientos. Se cultiva la comunión entre los hablantes, de una manera muy especial, a veces icónica, aunque respetando el espacio personal. La imagen del hablante merideño se parece bastante al hablante estudiado por Barros (1987) en São Paulo:

Las conversaciones cultas tendrán así por norma el poco compromiso de los hablantes, un cierto "distanciamiento" entre ellos, la ausencia explícita por un lado de conflictos o de polémicas, por otro de aproximaciones apasionadas, el disimulo de las relaciones más pasionales, la franca tensión conversacional y el carácter "dulce" o "flojo" de los lazos de interacción. Se construye de esa forma el hablante culto, distante, elegante, condescendiente, al menos en la apariencia evidenciada en la conversación. Esa condescendencia en la conducción del diálogo abre camino para que el hablante culto use las variaciones lingüísticas con tranquilidad (Barros, 1997:39, mi traducción).

Los conflictos y polémicas, ausentes en São Paulo, lo están también en Mérida porque también aquí se ocultan las relaciones pasionales. Sin embargo, puede decirse que el hablante merideño no es necesariamente distante, como describe Barros el suyo. Como vimos anteriormente, en el corpus de Mérida se da gran importancia a los acuerdos y se enfatiza la comunión con su interlocutor, aunque de forma respetuosa. Esto puede ser consecuencia de las diferencias que hay, desde el punto de vista social entre los dos conjuntos de materiales. Mientras Barros (1997) se refiere a un hablante "culto", de un alto nivel cultural, pero también económico, los 
nuestros proceden de todas las clases sociales. No hay ni que mencionar que São Paulo es una ciudad cosmopolita, mientras que Mérida es una pequeña ciudad universitaria.

\section{Conclusiones}

Estudiamos las normas de la cortesía en un corpus oral, recogido en $E l$ Habla de Mérida (Domínguez y Mora, 1999), evidenciadas a través de las reparaciones hechas a las transgresiones de esas normas y también a través de los intentos de los hablantes de concertar acuerdos entre ellos y evadir el conflicto. Para ello, seguimos de cerca estudios anteriores, como el de Barros (1997); esto nos permitió, por una parte, validar la metodología seguida en ese trabajo, y lograr nuestro propósito que era analizar las normas de cortesía verbal que rigen en una pequeña ciudad universitaria de los Andes venezolanos. Nuestro fundamento teórico está en Lara (1976); pues este autor explica detenidamente las razones por las cuales un estudio sobre las normas no puede cuantificarse.

Con relación a nuestros hallazgos, encontramos que esas reparaciones se hicieron, en este corpus, a través de estrategias como la sustitución de términos, el uso de omisiones y eufemismos y la atenuación que se llevó a cabo a través de diminutivos, por ejemplo. El uso de estrategias de consenso se dio a través de las marcas explícitas de acuerdo, los marcadores de interacción y las repeticiones.

Revisamos algunos estudios sobre la cortesía verbal, pertinentes para nuestro análisis, e hicimos también algunas observaciones teóricas sobre la cortesía. Consideramos la cortesía como un conjunto de normas dirigidas hacia el comportamiento social, y por lo tanto diferentes de las reglas gramaticales, relativas a la norma lingüística; este sistema tiene como función primordial la unificación del mismo y consecuentemente permite evitar el conflicto. Concluimos que la cortesía es una normativa que se registra en la función interpersonal y que se fundamenta en el lenguaje. En efecto, la cortesía verbal es quizás el sector más importante de la institución de la cortesía.

Partiendo del supuesto de que cuando los hablantes siguen un conjunto de normas determinado asumen también un ideal indagamos también 
sobre el ideal de persona que proyectan las normas de cortesía en El Habla de Mérida: en la cortesía positiva, el de una persona amable, conocedora de la lengua, que evade los temas impropios; en la cortesía negativa, la imagen de una persona que también sabe salir firme, aunque suavemente, a la defensa del territorio propio y que respeta el de los otros. Esta búsqueda nos lleva, consecuentemente, a la definición de la identidad del grupo observado.

Por tratarse de una investigación exploratoria no buscamos variación sociolingüística; aunque a grandes rasgos puede decirse que tampoco parece haber grandes diferencias entre los hablantes, en este particular. Sin embargo, al comparar la imagen del hablante de este corpus con el descrito por Barros (1997) encontramos que la del merideño es de una persona amable, no conflictiva, modesta y respetuosa de los demás. Su manera de hablar recuerda al hablante culto de São Paulo, descrito por Barros (1997) aún cuando parece distinguirse de aquél, en su propensión por lograr la comunión con el participante, a propiciar acuerdos y a crear lazos de interacción fuertes. Es posible que el origen de esto sea, precisamente, el hecho de que el hablante estudiado por Barros (1997) es un hablante culto y cosmopolita, mientras que los del corpus de Mérida, una pequeña ciudad andina, se mueven en todo el espectro social.

El hecho de que dos grupos tan disímiles, por hablar lenguas diferentes, habitar países distintos aunque del mismo continente, y pertenecer a clases sociales que no pueden compararse, nos hace elevar nuevamente la inquietud sobre la universalidad de al menos algunas normas de cortesía, y la pregunta sobre por qué parece imperar, en este ámbito, el mismo ideal de hablante. Seguramente habrá características que permitan distinguir las normas imperantes y por consiguiente la identidad propia de dos comunidades de habla tan disímiles. La respuesta a estas interrogantes sobrepasa la meta de nuestro trabajo y podría ser objeto de futuras investigaciones.

Aprovado em março de 2002. 


\section{REFERENCIAS}

Álvarez, A., C. Joven y P. Palm. 2000. Las reparaciones en El Habla de Mérida. Ponencia presentada en la 50 Convención Anual de ASOVAC.

Barros, D. L. Pessoa De. 1993. Procedimentos de reformulação: a correção. Preti, Dino (org.) Análise de textos orais. São Paulo. FFLCH/USP.

Barros, D. L. Pessoa de. 1997. A propósito do conceito de discurso urbano oral culto: definições e imagens. En: Preti, Dino (ed.). $O$ discurso oral culto. São Paulo: Editora Humanitas, FFLCH/USP: 29-43.

Bello, A. 1847/ 1972. Gramática. Caracas: Ministerio de Educación.

Briz, A. 1994. La atenuación en la conversación coloquial. Una categoría pragmática. En: Cortés Rodríguez (ed.) 1995 El español coloquial: actas del I Simposio sobre análisis del discurso oral. Almería, Universidad de Almería: Servicio de Publicaciones.

Brown, P, y\& S. C. Levinson. 1987. Politeness. Some universals in language usage. Cambridge: University Press.

Carreño, J. A. 1999. Manual de urbanidad y buenas maneras. Bogotá: Panamericana.

Chomsky, N. 1965. Aspects of the Theory of Syntax. Cambridge: M.I.T Press.

Coseriu, E. 1967. Teoría del Lenguaje y Lingüística General. Madrid: Gredos: 11-113.

Domínguez, Carmen Luisa. 1996. El Habla de Mérida: Un corpus de estudio En: Lengua y Habla 1.2: 46-55. Mérida: Universidad de Los Andes.

Domínguez, C.L (en prensa). No es cómo se dice sino lo que se dice: correcciones y repeticiones en el habla niño-adulto. Letras: Caracas: IUPC.

Domínguez, C.L. y A. Álvarez (en prensa) Los marcadores de interacción El Habla de Mérida. Lengua y Habla. Mérida: Universidad de Los Andes.

Domínguez, C. L. y E. Mora. 1998. El Habla de Mérida. Mérida: Universidad de Los Andes.

Dürkheim, É. 1993. Las reglas del método sociológico. Madrid: Morata.

Fairclough, N. 1992. Discourse and Social Change. Cambridge: Polity Press. FASOLD, R. 1984. The Sociolingüisticis of Society. London: Basil Blackwell.

FASOLD, R. 1990. The Sociolinguistics of Language. London: Basil Blackwell. Fishmann, J. 1972. Advances in the sociology of language. The Hague: Mouton. Goffman, E. 1967. Interaction Ritual. New York: Pantheon Books.

GonzÁlez Stephan, B. 1989. Silenciamiento y ortopedia de las lenguas salvajes (acerca de la lengua nacional en el siglo XIX). Perl, Matthias 
y Klaus Pörtl (eds.) Identidad cultural y lingüística en Colombia, Venezuela y en el Caribe hispánico. Tübingen: Niemeyer.

Grice, P. 1975. Logic and Conversation. Cole, P \& J.L. Morgan (eds.) Syntax and semantics, 3. Speech Acts: 41-58.

Guevara, M. 1998. Buenos modales. Nueva guía de comportamiento, etiqueta y urbanidad. Caracas: Los Libros de El Nacional, C.E.C.

Haverkate, H. 1994. La cortesía verbal. Estudio pragmalingüístico. Madrid: Gredos.

HJelmslev, L. 1972. Ensayos Lingüísticos. Madrid: Gredos.

LARA, L. F. 1976. El concepto de norma en lingüística. México: El Colegio de México.

Moliner, M. 1996. Diccionario de uso del español. Novell. Inc.

Moré, B. 1999. Lengua, gramática y poder en la obra de Andrés Bello. Universidad de Los Andes. Trabajo de grado para obtener el título de Magister Scientiae en Lingüística.

Puga, J. 1997. La atenuación en el castellano de Chile, un enfoque pragmalingüístico. Valencia: Universitat de València, Grupo de Estudis Iberoamericans.

Real Academia Española. 1970. Diccionario de la Lengua Española. Madrid: Espasa - Calpe.

Sacks, H. Schegloff, E. y Jefrerson. 1974. A simplest systematics for the organization of turn-taking in conversation. Language, 50: 696-735.

SeArle, John R. 1997. La construcción de la realidad social. Barcelona: Paidós.

Sirola, Susana. 2000. Urbanidad, cortesía y buenas maneras. Bibliografía comentada. Informe de pasantía. Escuela de Letras, Mérida: Universidad de Los Andes. 